\title{
Evaluation of Beam-Flange (BF) Bolts on Behavior of New BBCC Connection with Preferred Support in Modularized Prefabricated Steel Structures
}

\author{
Azizi Naserabad Alifazl ${ }^{1 *}$, Ghasemi Mohammad Reza ${ }^{1}$, Shabakhty Naser ${ }^{2}$ and Ghohani Arab Hammed ${ }^{1}$ \\ ${ }^{1}$ Department of Civil Engineering, University of Sistan and Baluchistan, Zahedan, Iran \\ ${ }^{2}$ Department of Civil Engineering, Iran University of Science and Technology, Tehran, Iran
}

\begin{abstract}
The proposed prefabricated Bolted Beam-to-Column Connection (BBCC) has been introduced to remove the problems of continuous/box columns and to show such merits as high-quality factory fabrication, easy transportation/ erection/resumption, investment return, prefabrication, and modularization; this paper aims at numerically studying the cyclic behavior of this novel connection with a preferred support shape. The preferred support and covering plate are proposed to enhance the number/diameter of BF bolts and more economic efficiency. To this end, first a similar connection was modeled, and the numerical and experimental results were compared and validated. Then, three models were made to study the behavior of the exterior connections under cyclic load. Models variations included three different cross section of beam-flange (BF) connection bolts; the bases adopted for the model behavior were the AISC seismic provision requirements. The failure had two different behavior modes. The connection behavior was very sensitive to the $B F$ bolt cross sectional area meaning that an increase in this area considerably changed the connection behavior and all the AISC specific moment frame requirements including the failure mode, rigidity, ductility, moment capacity, rotational capacity, and ultimate rotation were met.
\end{abstract}

Keywords: Bolted connection; Modular prefabricated; Finite element analysis; Cyclic Load; Box column

\section{Introduction}

The 1994 Northridge earthquakes revealed a series of undesirable brittle failure modes in welded beam-to-column joints that undermined the high seismic performance of steel moment-resisting frames [1]. Failure of welded connections in Northridge earthquake, raised attention to the need for quality and speed of implementation, possibility of fabricating of bolted connections in the factory, and suitable rotational capacity of bolted connections that reduces need to beam and column ductility. The use for high strength steel and high quality of factory welding has pushed welded to bolted steel structures $[2,3]$. Due to those reasons and also easy implementation of segments in the site, bolted connections were found quite suitable. Thus, due to its importance, end-plate connection is the one considerable research has been carried out on, such as strengthened by stiffener member assemblies [4], connecting by blind bolts [5], effect of bolts arrangements in end-plate and T-stub joints [6], strengthening of the connection regions with additional bolts row [7] the behavior of joints subjected to severe impulsive loading [8], effect of stiffeners on the joint behavior [9], effect of shape memory alloy bolts on the joint performance [10].

Box columns are quite popular in high earthquake-prone regions because, compared with $\mathrm{H}$-section columns, they have such variety of advantages as higher strength and torsional stiffness, equal strength and stiffness with respect to the two axes of the column section, better corner column performance in steel moment frames, higher moment of inertia around the main axes, no need for column lateral bracing, reduced strength deterioration, optimum use of materials, and minimum surface painting/maintenance costs $[11,12]$.

Despite their merits, box column-beam connections face two problems:

1. Difficulty inside-box access for welding continuity plates and
2. Difficulty in transportation, (re)erection, resumption, prefabrication, and modularization as regards continuous column fabrication and erection in several stories.

The first problem was studied and solved by some researchers such as, welded joint by passing a vertical plate through the column [13], welded joint by a diagonal through plate [14], the ConXL bolted joint system [15]. The second problem solved recently in prefabricated steel structures joints that the columns are applied as single in onestory such as bolted-welded joint [16,17], and bolted joint [18]. In the latter, beams are in the form of trusses and although the single-story, discontinuous column fabrication facilitates the prefabrication of small segments for easier transportation and prefabrication of roof parts outside the site and erecting inside it, it elongates fabrication period making I-section profiles more appropriate because of the reduced fabrication time and no need for welding.

To solve these problems in I-beam to box-column joints, a new type of Bolted Beam-to-Column Connection (BBCC) for modularized prefabricated steel structures was proposed $[19,20]$. The proposed connection is used to join separated and prefabricated beams and columns, and can facilitate the rapid assembly of members on site. As shown in Figure 1, the proposed connection consists of one BBCC support, upper column with a base plate, lower column with a base

*Corresponding author: Azizi Naserabad Alifazl, Department of Civil Engineering University of Sistan and Baluchistan; Zahedan, Iran, Tel: 98-54-33446251; E-mail: azizialifazl@pgs.usb.ac.ir

Received July 03, 2017; Accepted July 07, 2018; Published July 14, 2018

Citation: Alifazl AN, Reza GM, Naser S, Hammed GA (2018) Evaluation of BeamFlange (BF) Bolts on Behavior of New BBCC Connection with Preferred Support in Modularized Prefabricated Steel Structures. J Steel Struct Constr 4: 142. doi: $10.4172 / 2472-0437.1000142$

Copyright: @ 2018 Alifazl AN, et al. This is an open-access article distributed under the terms of the Creative Commons Attribution License, which permits unrestricted use, distribution, and reproduction in any medium, provided the original author and source are credited. 
Citation: Alifazl AN, Reza GM, Naser S, Hammed GA (2018) Evaluation of Beam-Flange (BF) Bolts on Behavior of New BBCC Connection with Preferred Support in Modularized Prefabricated Steel Structures. J Steel Struct Constr 4: 142. doi: 10.4172/2472-0437.1000142

Page 2 of 12

plate, beams with holed flanges, $\mathrm{C}$ bolts, and BF bolts. BBCC support is the main difference (and also merit) of this connection compared with other beam-column connections. As shown in Figure 1, BBCC support can be fabricated separately in two general configuration in the factory and then rapidly assembled with prefabricated beams and columns on site.

As shown in Figurela, the main BBCC support is formed by one base plate, four corner plates, one continuity plate, two vertical plates, four side stiffeners, and two middle stiffeners which are welded together in the factory. Columns consist of a box profile, gusset plates, and holed base plates that are (pre)fabricated in the factory. $\mathrm{C}$ and BF holes are drilled in the base plates to join $\mathrm{C}$ and BF bolts. $\mathrm{C}$ bolts are applied to join columns to the BBCC support. BF bolts connect the beams flanges to the base plates of columns and BBCC support.

Beams are made from I-shape profiles that facilitate quick fabrication in the factory and rapid erection on site. The beam flanges are drilled in the factory to join BF bolts (Figure 1).

According to Figure $1 \mathrm{~b}$ and Figure 2, the erection order is to erect the lower story columns, assemble the BBCC support, tighten the lower
C bolts, place the beams, tighten the lower BF bolts, place the upper story columns, tighten the upper $\mathrm{C}$ bolts, and finally tighten the upper BF bolts; the completed connection is shown in Figure 1c and Figure 2.

Other advantages of the proposed connection include easy (re) installation, full resumption, high quality, easy transportation, no need for heavy machinery, quick erection, quick investment return, economic profitability, prefabrication, modularization, capability of separate beam-roof assembly prefabrication to be installed on lower columns/prefabricated BBCC connections, installation capability under different weather conditions, combination capability with various roofing systems, replacement capability of disaster-caused defective members, capability of creating strong skeletons for prefabricated systems of containers in the desired number of stories.

The effects of three different support shapes on the exterior connection behavior was studied as shown in Figure 3 [20]. Three supports were included single beam connection (SBC) support with continuity plate (Figure 3a), continues beam connection $(\mathrm{CBC})$ support Figure $3 \mathrm{~b}$, and single beam connection (SBC) support without continuity plate (Figure 3c). It had been achieved that single beam
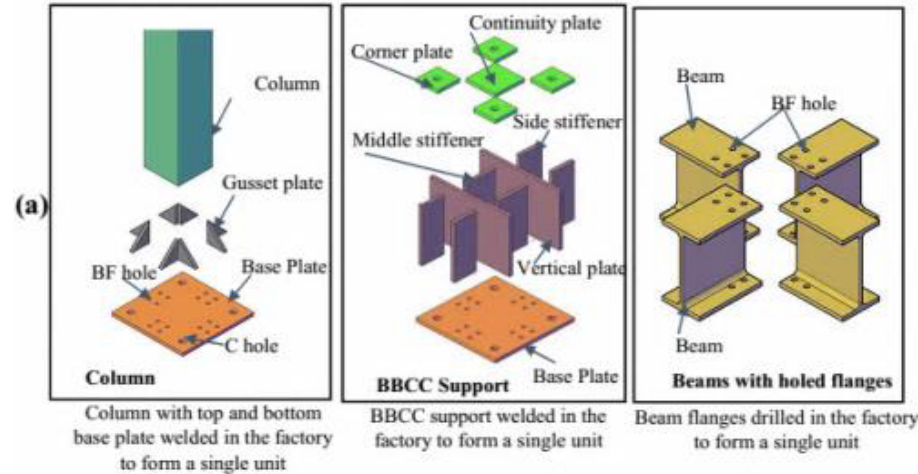
to form a single unit

(b)
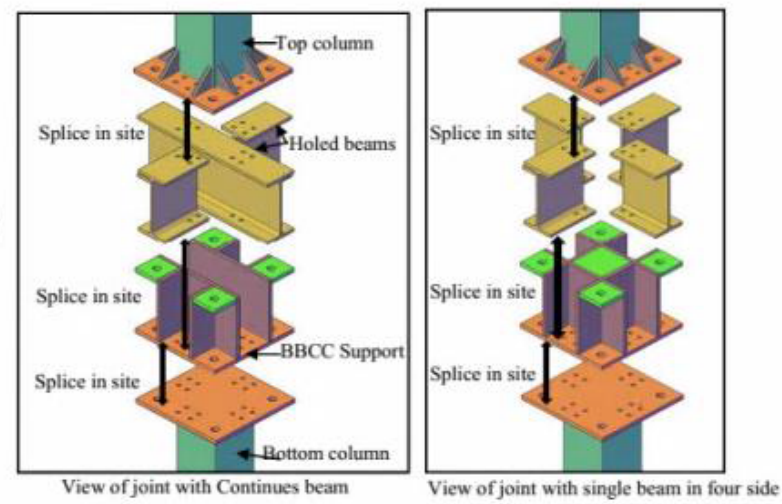

(c)

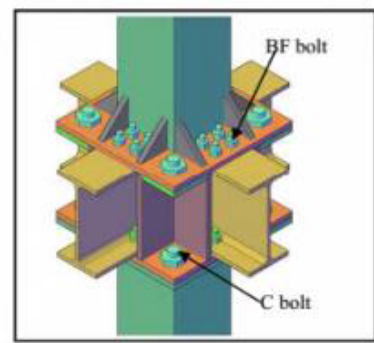

Figure 1: Structural diagram of the BBCC connection (a) Exploded view of components (b) Assembly drawing (c) Assembled BBCC joint. 


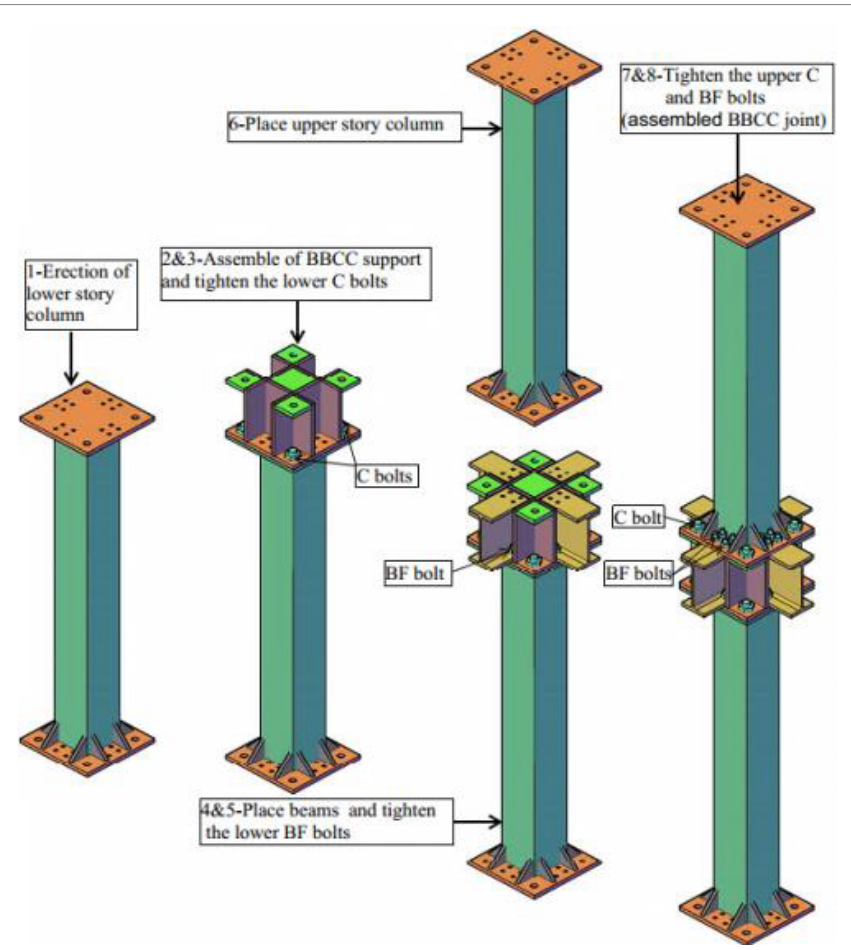

Figure 2: Erection and assembly order of members on site.
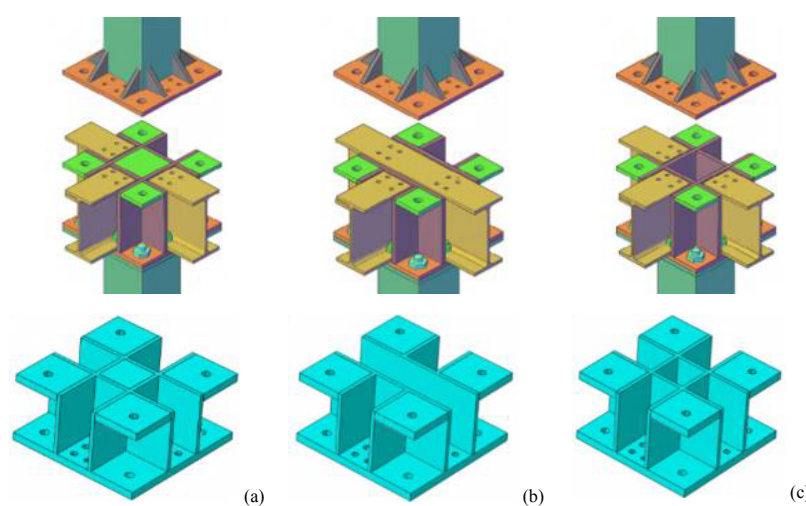

Figure 3: Different support shapes of side joints (Azizi Naserabad and others, 2018) (a) Single beam support with continuity plate SBC5 (b) Continues beam support CBC4 (c) Single beam support without continuity plate SBC4.

connection (SBC) support with continuity plate (Figure 3a) had the best support shape (Figure 3).

Codes require that the center-to-center and center-to-edge bolt spacing requirements be met in the perforated plate design. We recommend, for economic efficiency, that if more than four large diameter bolts are needed, use is to be made of the connection plan shown in Figure 4 . The preferred support Figure $4 \mathrm{~b}$ and covering plate are proposed to enhance the number/diameter of BF bolts and more economic efficiency.

This paper aims at studying the cyclic behavior of the proposed novel connection numerically through the FEM for nonlinear behavior modeling of the exterior BBCC. Since no test results exist for this connection, in this study, first a connection similar to that tested [16] was modeled to evaluate the accuracy of the FE model and the results were compared with the existing test results and model validation was investigated. Then, considering the BBCC and tested connection similarity, the exterior BBCC connection (one-side beam) behavior was numerically investigated under cyclic load. Models' variations including three different $\mathrm{BF}$ bolt arrangements are presented in Table 1. Effects of the BF bolts cross-section on the failure mode, rigidity, ductility, rotational capacity, moment capacity, maximum force/ moment, and ultimate rotation and displacement under cyclic load were determined in accordance with the AISC provisions using forcedisplacement and moment-rotation hysteresis and skeleton curves.

\section{Numerical Modeling}

The numerical modeling included the design of the elements of the connection models, validation, naming and geometrical specifications, materials specifications, loading and support conditions, and FE modeling. The connection was designed based on the AISC $[21,22]$, and the seismic criteria of Iran Code of Connections, and beams and 


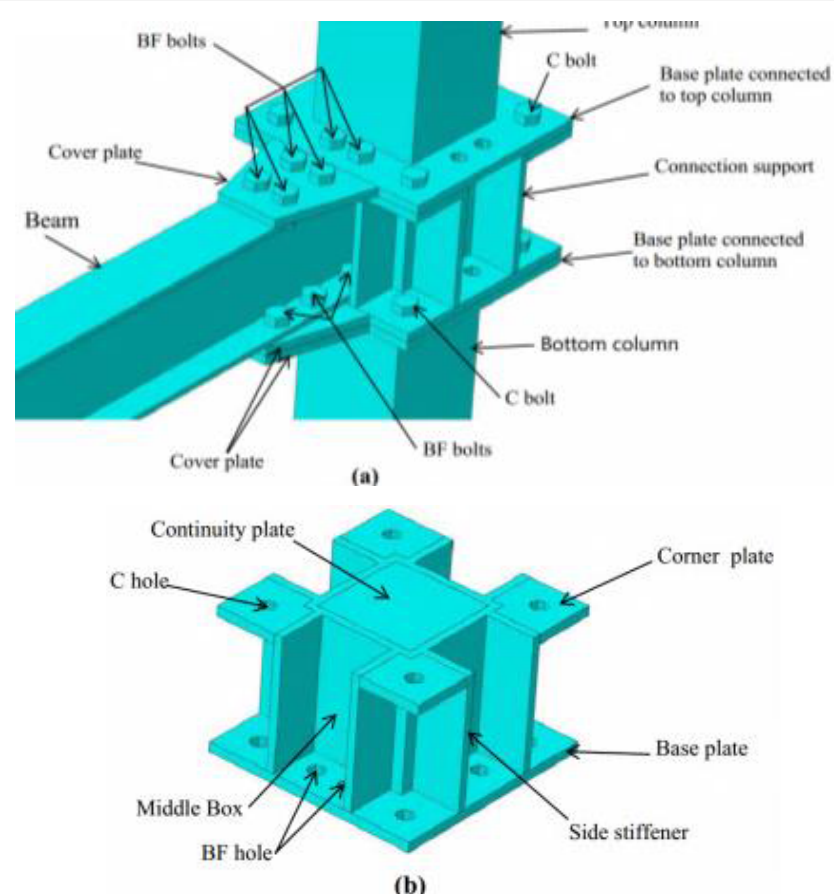

(b)

Figure 4: Connection sketch with large size and diameter of BF bolts (a) connection (b) preferred support.

\begin{tabular}{|c|c|c|c|}
\hline Connection charactristics & F support, and $2 \varnothing 18 \mathrm{BF}$ bolts & F support, Cover plate and $4 \emptyset 18 \mathrm{BF}$ bolts & F support, Cover plate and $6 \emptyset 18$ BF bolts \\
\hline Connection shape & & & \\
\hline & F2B & FC4B & \\
\hline
\end{tabular}

Table 1: Different models with F-support and various bolt arrangement.

columns were selected according to weak beam-strong column criterion. Connection design included geometrical and structural design of the connection elements; geometrical design was according to the beam/ column geometry considering the bolts spacing requirements, and in the structural design, bolts' diameters and plates' thicknesses were determined based on maximum beam/column capacity considering the effects of the bolts pre-stressing forces. In all models, beams and columns were unchanged and the BF bolts arrangements changed according to Table 1 .

\section{Validation}

To validate, a connection similar to that tested [16] was modeled with bolts, and results were compared and validated. Figure 5 shows the test plan/picture, FE models, meshing pattern, and failure mode (both experimental and numerical) of this connection. As shown, a plastic hinge has been formed in the bolted FE model similar to that of the test model.

Figure 6 shows the load-displacement hysteresis and skeleton curves at the loading point; as shown, the FE model results show good precision both qualitatively and quantitatively compared with experimental results. Therefore, considering their similarity, validity of the FE models verifies that of the novel BBCC as well. The differences between numerical and experimental curves among hysteresis curves [23] studies can have a variety of sources, often being a direct consequence of the simplifications introduced in the numerical modeling. Among these factors are:

1. Imperfections originated from the assembly of the tested models;

2. The effects of residual stresses; and

3. Representation of stress-strain behavior for materials in the FE models.

\section{Naming and geometrical specifications}

The preferred support shape, since plates dimensions limit the use of more and larger diameter BF bolts, use will be made of the single beam connection (SBC) support with continuity plate and covering plates that is named flange(F)-support (Figure 4) if center-to-center and center-to-edge bolt spacing Code requirements are not met. The models are named based on F-support type, existence or absence of cover plate, and number of BF bolts. The connection dimension details, including the support, plates, cover plates, and sections of the beam and column are shown in Figure 7; in all models, beams and columns are fixed. In the model called F2B, F refers to the support type and $2 \mathrm{~B}$ 


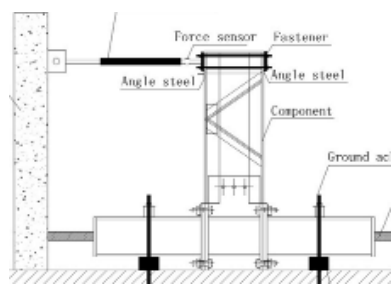

(a) Sketch of the test loading device

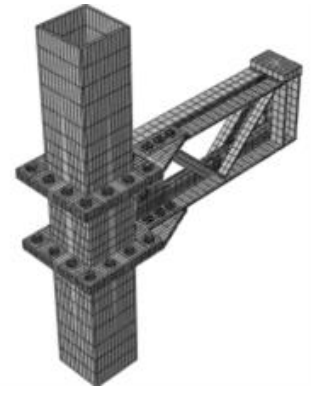

(c) bolted simulation mesh

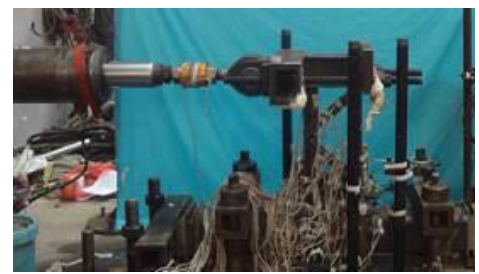

(b) Photograph of the testsetup

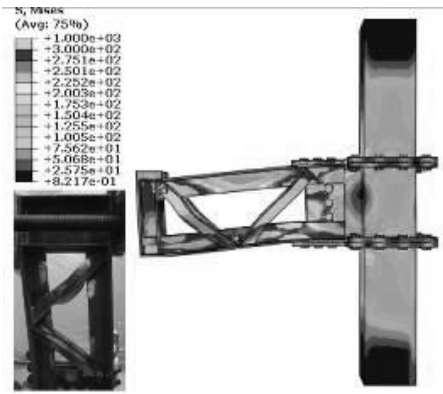

(d) failure modes

Figure 5: Verification by similar tested joint(Liu and others, 2015(a)) (a) Sketch of the test loading device (b) Photograph of the test setup (c) bolted simulation mesh (d) failure modes.

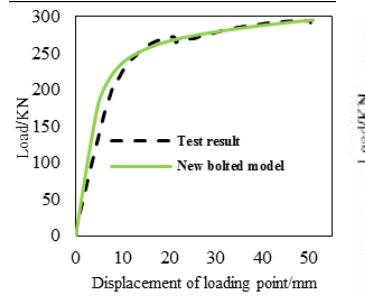

(a)

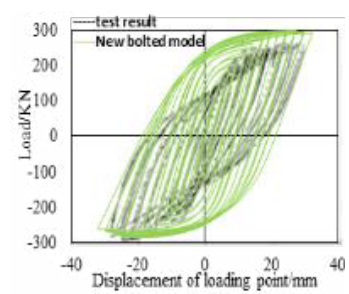

(b)

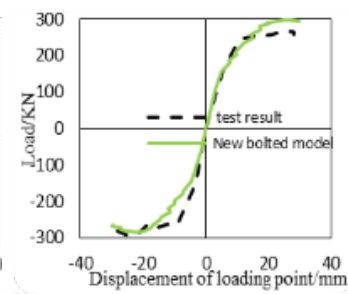

(c)

Figure 6: Verification curves of similar tested connection (Liu and others, 2015(a)) (a) Load-Displacement curve under static load (b) hysteric curve under cyclic load (c) Load-Displacement skeleton curve.

is the two $18 \mathrm{~mm}$ diameter BF bolts. In the model named FC4B, FC means F-support with cover plate, containing four $18 \mathrm{~mm}$ diameter BF bolts. The model called FC6B, has F-type support, cover plate, and six $18 \mathrm{~mm}$ diameter BF bolts. Cover plates are used in FC4B and FC6B models.

\section{Material properties}

The material used to make beams, columns, and connection supporting components is ST52 steel with a yield stress of $360 \mathrm{MPa}$, an ultimate tensile strength of $520 \mathrm{MPa}$, and $20 \%$ plastic strain. The bolts' material is A490 steel with a yield stress of $900 \mathrm{MPa}$, an ultimate tensile strength of $1000 \mathrm{MPa}$, and $10 \%$ plastic strain. In all components, the steel density was $7850 \mathrm{~kg} / \mathrm{m}^{3}$, the elastic modulus is $209 \mathrm{GPA}$, and the Poisson ratio is 0.3 .

\section{Loading and boundary conditions}

Connection has been introduced as an exterior one and, as shown, both ends of the upper and lower columns are hinged while the beam end is free with the concentrated load being applied at its free end (Figure 8).
The load applied at the beam end is a Code cyclic load [21,22] in this figure, the cyclic load is in terms of the beam lateral rotation (Figure 9). In Table 2, this load is presented in the form of the displacement applied at the free end of the beam. Bolts have been divided, from the middle, into two separate parts to apply the pre-stressing force; pretension loads applied on M18 bolts is $140 \mathrm{KN}$. Loading is applied in two steps, first the pretension load on the bolts and then the cyclic load on the beam end.

\section{Finite element model}

ABAQUS three-dimensional nonlinear finite element model of four specimens was prepared as shown in Figure 10. Bolts too are defined in the model, and to enhance precision, all the model elements are turned into structured meshes through partitioning. The beams, columns, plates, and bolts were discretized using three-dimensional solid (brick) elements. A fine solid-element mesh is used to model panel zone region more accurately and a coarse solid-element mesh is used to model remainders of the subassemblies. The analyses account for material nonlinearities through metal plasticity theory based on the Von Misses yield criterion. Hinged boundary conditions were used to support top and bottom of the columns. Contact of steel surfaces is 
Citation: Alifazl AN, Reza GM, Naser S, Hammed GA (2018) Evaluation of Beam-Flange (BF) Bolts on Behavior of New BBCC Connection with Preferred Support in Modularized Prefabricated Steel Structures. J Steel Struct Constr 4: 142. doi: 10.4172/2472-0437.1000142

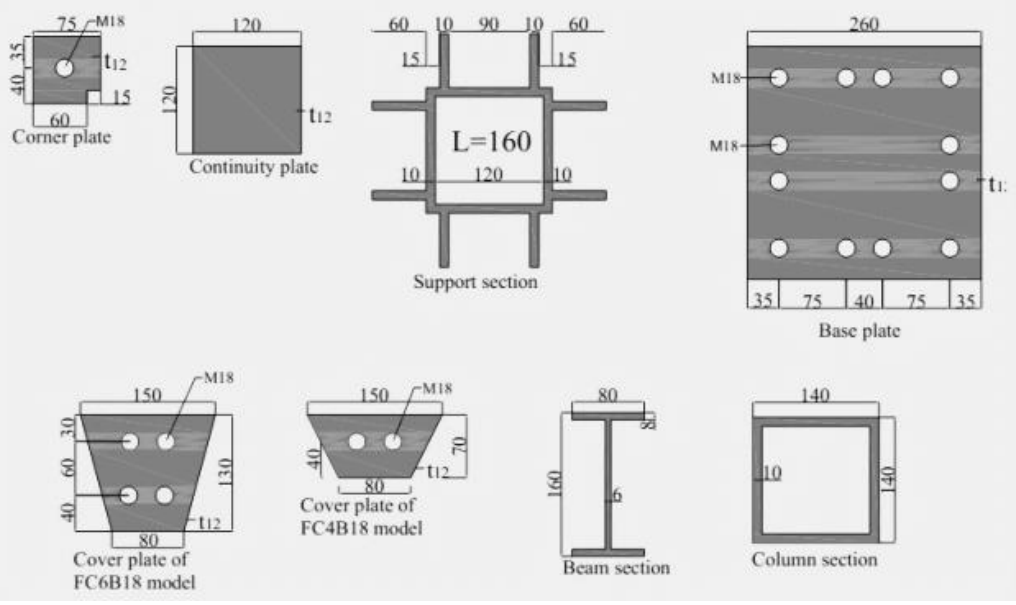

Figure 7: Dimensional details of connection elements.

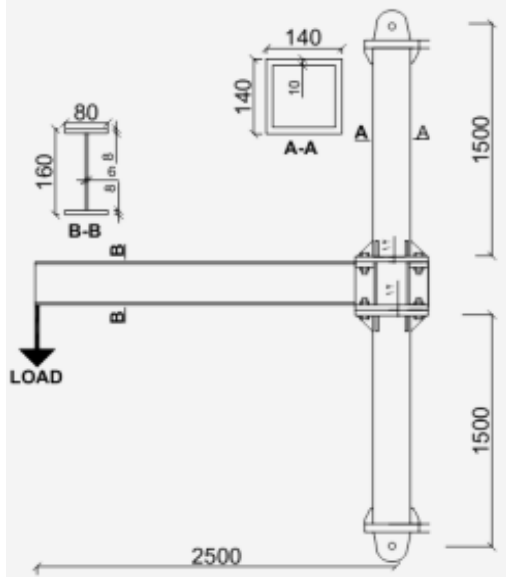

Figure 8: Sketch of simulations.

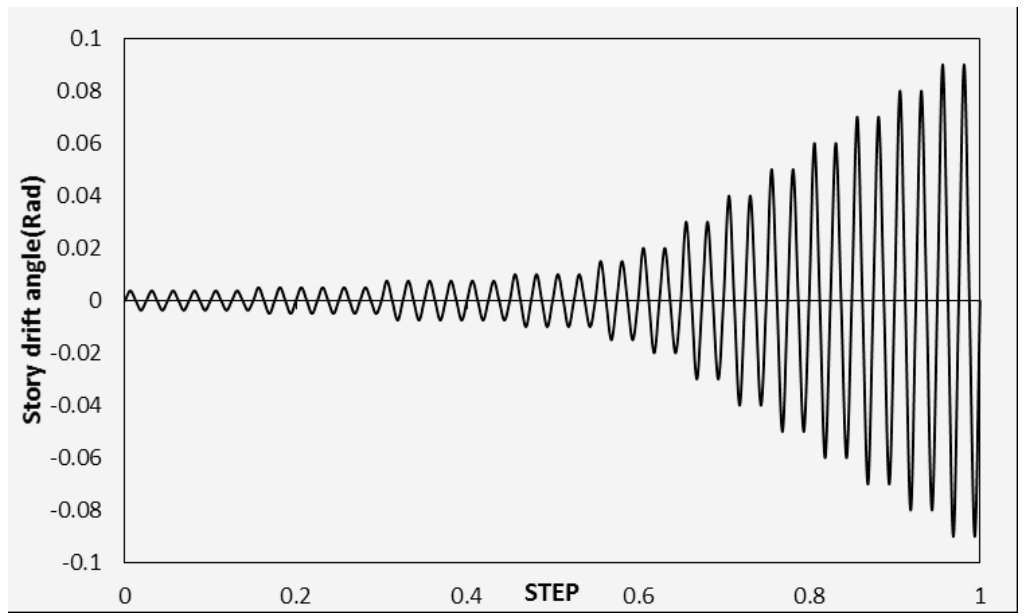

Figure 9: AISC cyclic load diagram applied to beam tip (AISC/ANSI 314, 2010).

\begin{tabular}{|l|c|c|c|c|c|c|c|c|c|c|c|c|c|}
\hline Cycle number & 6 & 6 & 6 & 4 & 2 & 2 & 2 & 2 & 2 & 2 & 2 & 2 & 2 \\
\hline Displacement & 9.375 & 12.5 & 18.75 & 25 & 37.5 & 50 & 75 & 100 & 125 & 150 & 175 & 200 & 225 \\
\hline
\end{tabular}




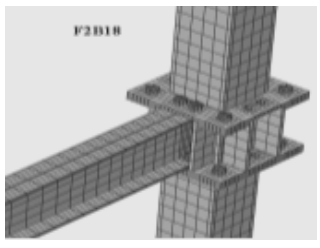

F2B

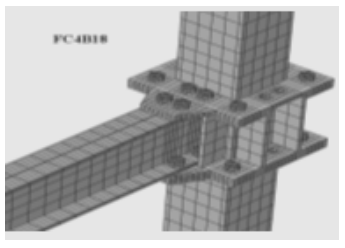

FC4B

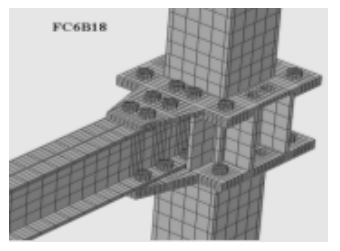

FC6B

Figure 10: FEM models.

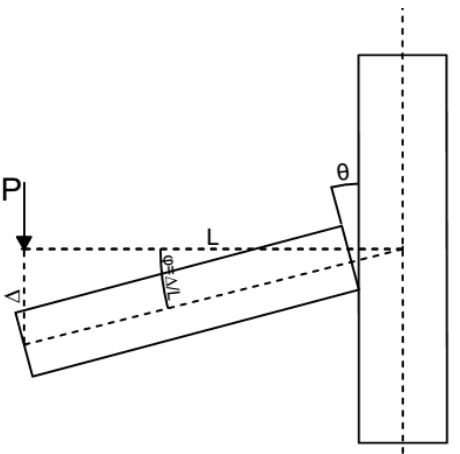

(a)

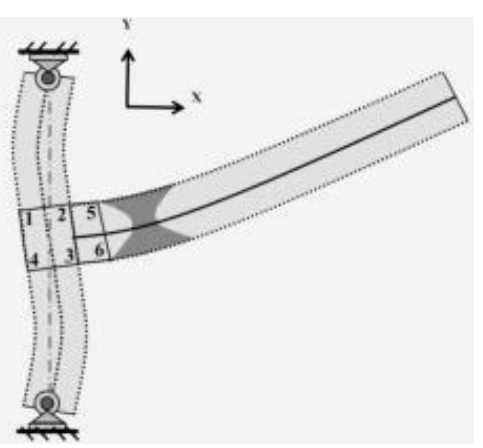

(b)

Figure 11: Displacement and rotations of beam (a) angles and obtaining of $\varphi$ angle (b) definition of point for obtaining of $\theta$ angle.

defined hard with friction coefficient 0.35 according to AISC provision $[21,22]$. Welded connections and contact of bolts head to plate surfaces are defined as tie constraint and other contact of surfaces as interaction. Kinematic hardening and geometric nonlinearities are assumed for cyclic analysis.

\section{AISC Requirements and Provisions}

According to the AISC Code, a connection is to meet the following requirements to be able to have the seismic provisions and requirements of special moment frames:

1. A Plastic hinge is to be formed in the beam.

2. The connection rigidity is to be fully restrained.

The connection stiffness can be defined as beginning slope of the M- $\theta$ curve, i.e., $\frac{M_{s}}{\theta_{s}}$ According to AISC (AISC/ANSI 360, 2010), If $K_{s} \geq \frac{20 E I}{L}$, the connection is considered as fully restrained, if $K_{s}<\frac{2 E L}{L}$, the connection is considered as simple. Connections having stiffness values between these two limits will be partially restrained. L and EI are the length and bending rigidity, respectively, of the beam.

1. The $4 \%$ corresponding moment is to be more than $80 \%$ of the beam plastic moment.

AISC [21,22] provisions indicate that if moment resistance at $4 \%$ total story drift is more than $80 \%$ of the beam plastic moment, the connection will meet the AISC seismic requirements for special moment frames.

1. Rotational capacity and ultimate rotation are to be more than 3 and $4 \%$, respectively.

2. The ductility coefficient is to be more than 3.5 .

\section{FE Analysis and Discussion}

To evaluate models' behavior the FE analysis results are presented and then connections behavior include, failure mode, performance curve, rigidity, ductility, rotational/moment capacities, maximum force/moment, and ultimate displacement/rotation are discussed and compared.

\section{Analysis parameters}

The FE analyses of the connection models have been done using the FE computer program [24] and the results have been derived based on $\theta$ and $\varphi$ angles defined in Figure11a. According to the AISC Code, to find the connection stiffness, use is to be made of the $M-\theta$ curve (M is the moment at the beam fixed end joined to the column and $\theta$ is the angle between beam and column). The connection stiffness is obtained by the slope of $\mathrm{M}-\theta$ curve in the beginning point. According to the Figure $11 \mathrm{~b} \theta$ is found as follows:

$$
\theta=\frac{u 5-u 6}{h}-\frac{u 2-u 3}{h}
$$

Where, $u_{i}$ are the displacements of the points indicated in Figure $11 \mathrm{~b}$ along the $\mathrm{x}$-direction and $h$ is the beam height.

The $M-\varphi$ curve is used to determine the connection rotational capacity, ultimate rotation, and moment resistance where $\varphi$ is the lateral drift angle found as follows in Figure 11a.

$$
\varphi=\frac{\Delta}{L}
$$

Where $\Delta$ is the beam end displacement and $\mathrm{L}$ is the distance between column center and beam free end (beam length).

The beam end yield and ultimate displacements are used to determine the ductility coefficient which is found as follows:

$$
\mu_{u}=\frac{\Delta_{\mathrm{u}}}{\Delta_{\mathrm{y}}}
$$


Where $\Delta_{\mathrm{u}}$ and $\Delta_{\mathrm{y}}$ are the ultimate and yield displacements respectively.

The ultimate and yield lateral drift angle are used to determine the connection's rotational capacity which is found as follows:

$$
\varphi_{\mathrm{p}}=\varphi_{\mathrm{u}}-\varphi_{\mathrm{y}}
$$

Where $\varphi_{\mathrm{u}}$ and $\varphi_{\mathrm{y}}$ are the ultimate and yield lateral drift angles, respectively (Figure 11).

\section{Failure mode and von Misses stress}

Figure 12 shows the models' failure modes, beam plastic hinge formation, and von Misses stress diagram under static and cyclic loads. As shown, there is torsion in the beam under cyclic load. The cyclic motion of cyclic load after the formation of plastic hinge and loss of lateral resistance is caused the torsion. In F2B model, failure occurs in BF bolts because they are weak; as shown in Figure 12, maximum von Misses stress in this model equals the ultimate stress in BF bolts indicating their failure, but in FC4B and FC6B models, failure occurs in the beam at the holes where the beam cross section is weaker. Therefore, depending on the BF bolt cross-section, connection fails in two forms:

1. When BF bolt cross section is low, beam starts to yield, and stress in bolts reaches its ultimate value and fails before the beam plastic hinge formation is complete and

2. When BF bolt cross section is high, failure occurs in the beam at holes after the formation of the plastic hinge (Figure 12).

\section{Performance curves}

The hysteresis curves that are obtained from the cyclic loading can reflect the seismic performance of the joint, such as the elastic-plastic performance, ductile performance, stiffness and energy dissipation capacity. Thus, the hysteretic curves are the main basis for the evaluation of seismic performance. The skeleton curve is formed by connecting the peak points of each cycle on a hysteretic curve and reflects the yield load/moment and ultimate bearing capacity of a specimen [16].

To determine the models' seismic behavior, the P- $\Delta, \mathrm{M}-\theta$, and $\mathrm{M}-\varphi$ hysteresis and skeleton curves and their related numerical results are shown in Figures 13 and 14 and in Tables 3-5 respectively. For a better interpretation of the curves, first the positive and negative cases and important points (yield, maximum, and ultimate) are described Tables 3 and 4.

\section{P- $\Delta$ curve}

The P- $\Delta$ curve is used to obtain the yield and maximum forces, yield and ultimate displacements, stiffness degradation, and connection ductility. Since ultimate limits of the cyclic load applied in the displacement form are $\pm 225 \mathrm{~mm}$, curves interpretations will be done in comparison with these limits.

The P- $\Delta$ hysteresis curve of the F2B model Figure 13 shows that its maximum positive and negative displacements are less than the limits of the applied cyclic load, and specimens have failed in displacements less than these limits due to low cross section of the BF bolts (curve spindle shape is not complete). The P- $\Delta$ skeleton curve obtained for this models. Figure 14 shows low ductility and lower ultimate displacement than cyclic load limits.

The FC4B model curves Figure 13 and 14 show better performance compared to the F2B model, but again the hysteresis curve spindle shape (the cycle) is not complete because beam flange holes are weak. FC6B model has a very good performance, high ductility is achieved, and hysteresis curve spindle shape (the cycle) is complete because cover plate is added and number of BF bolts has increased. The ductility

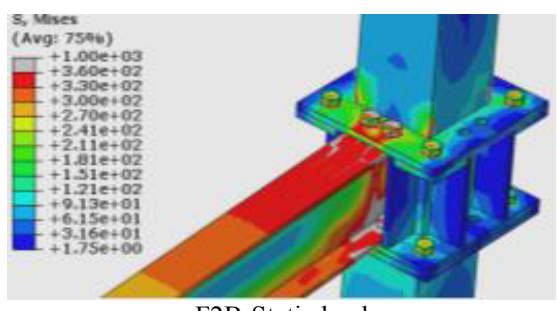

F2B-Static load

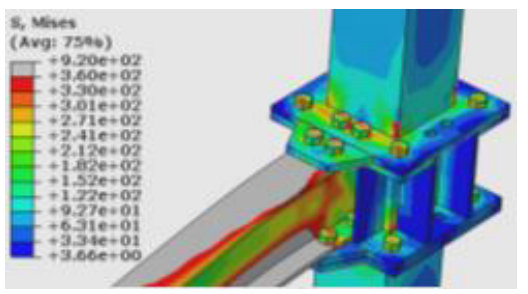

FC4B-Static load

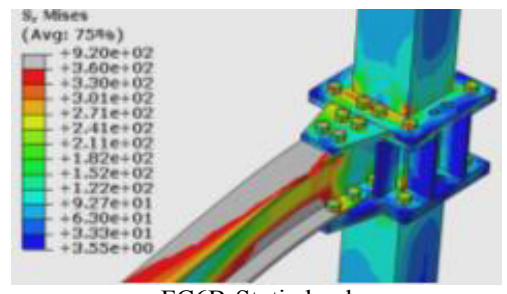

FC6B-Static load

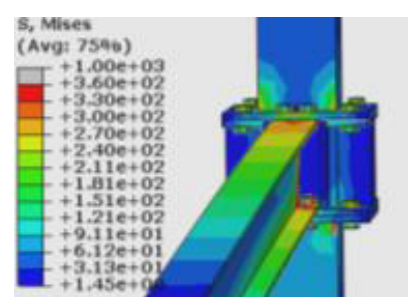

F2B-Cyclic load

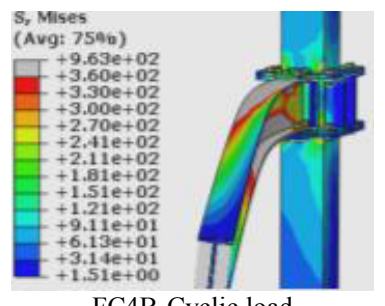

FC4B-Cyclic load

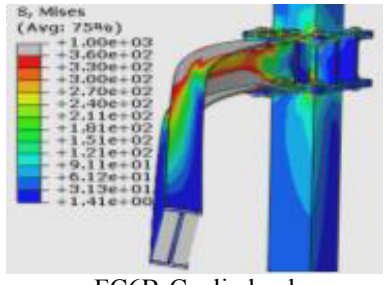

FC6B-Cyclic load

Figure 12: Failure mode and Von Misses stress of models under static and cyclic load. 

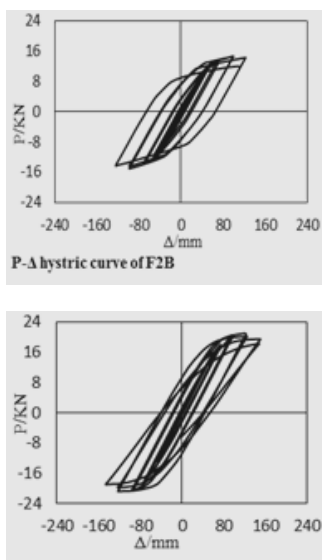

P-A hystric curve of FC4B

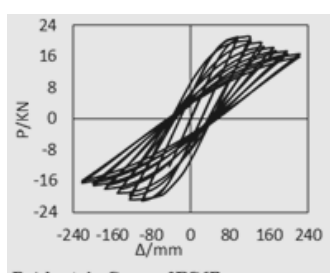

P-A hystric Curve of FC6B
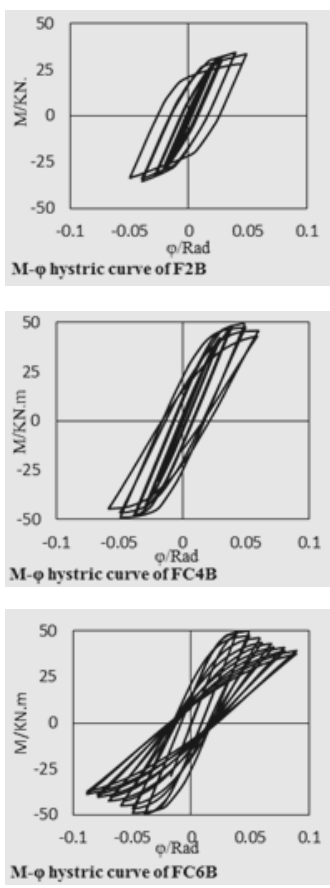

Figure 13: $P-\Delta, M-\theta, M-\varphi$ hysteric curves.
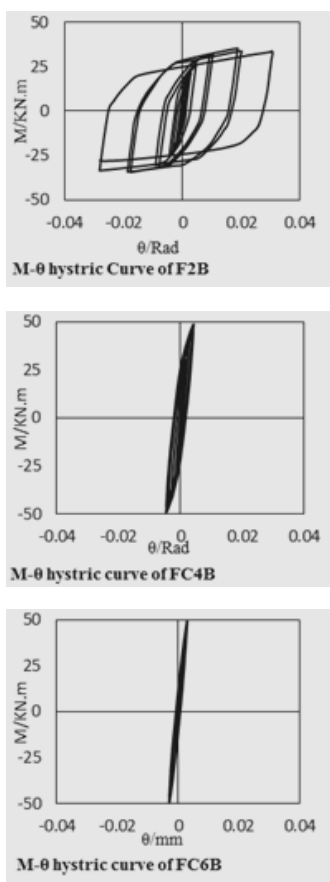

\begin{tabular}{|c|c|c|c|}
\hline 2EI/L & 20EI/L & Rigidity percent & Connection type \\
\hline 1523.5 & 15235 & $77 \%$ & PR \\
\hline 1523.5 & 15235 & $124 \%$ & FR \\
\hline 1523.5 & 15235 & $140 \%$ & FR \\
\hline
\end{tabular}

Table 3: Connection classification by comparison of beginning slope of M- $\theta$ skeleton curve with AISC provisions.

\begin{tabular}{|c|c|c|c|c|c|}
\hline Model & $M_{\max }(K N . m)$ & Mp(KN.m) & M0.04(KN.m) & $\frac{\boldsymbol{M}_{0.04}}{\boldsymbol{M}_{\boldsymbol{P}}}$ & $\frac{\boldsymbol{M}_{0.04}}{\boldsymbol{M}_{\boldsymbol{P}}}>0.8$ \\
\hline F2B & 34.4 & 46.2 & 34 & 0.74 & N.O.K \\
\hline FC4B & 48.7 & 46.2 & 48.5 & 1.05 & O.K \\
\hline FC6B & 49.5 & 46.2 & 49 & 1.061 & O.K \\
\hline
\end{tabular}

Table 4: Moment strength capacity of models in comparison to the AISC seismic provision requirements.

coefficients obtained from Eq. 3 and numerical values found from these curves are presented in Table 5 .

\section{M- $\theta$ curve}

The connection rigidity is found through the $\mathrm{M}-\theta$ skeleton curves (Figure 14); connections are classified by finding the slope of the beginning of the $\mathrm{M}-\theta$ skeleton curves. The low beginning slope in their skeleton curves indicate these models' lower rigidity. The FC6B model has the highest rigidity, and the F2B model has the lowest rigidity. Table 3 shows the connection models' classification using the beginning slopes of the $\mathrm{M}-\theta$ skeleton curves compared with the requirements of the AISC Code.

\section{M- $\varphi$ curve}

The yield and maximum moments, yield and ultimate rotations, and connection rotational and moment capacities are obtained through the $M-\varphi$ curve. Ultimate rotation is defined as one that corresponds to the moment reduced to $80 \%$ of the plastic moment (M0.8P), and if failure occurs faster, it will be defined as one that corresponds to the failure moment (MF); ultimate moment of this point is defined as that of either M0.8P or MF. Moment corresponding to $4 \%$ total story drift (M0.04) is defined as the ultimate rotation moment which is to be greater than the ultimate moment (MF/M0.8P). As shown in Figures 13 and 14 , all $\mathrm{M}-\varphi$ hysteresis and skeleton curves show ultimate rotations greater than $4 \%$; that of F2B is about 5\% and those of FC4B and FC6B are about 6 and $9 \%$ respectively; important connection performances (moment and rotational capacities) are obtained from these curves.

Table 4 shows the bending performance and moment capacity of connection models compared with the AISC seismic moment frame requirements and Table 5 presents the rotational capacity and performance indices obtained from P- $\Delta$ and M- $\varphi$ curves. Table 5

\section{Rigidity}

Rigidity is defined in M- $\theta$ skeleton curve (Figure 14), determined for models as explained in part 3 , and presented in Table 3 (as the slope of the beginning of this curve). Percent rigidity is found by dividing 
Citation: Alifazl AN, Reza GM, Naser S, Hammed GA (2018) Evaluation of Beam-Flange (BF) Bolts on Behavior of New BBCC Connection with Preferred Support in Modularized Prefabricated Steel Structures. J Steel Struct Constr 4: 142. doi: 10.4172/2472-0437.1000142

Page 10 of 12

\begin{tabular}{|c|c|c|c|}
\hline Model & F2B & FC4B & FC6B \\
\hline yield load; $\quad \mathrm{P}_{\mathrm{y}^{+}}(K N)$ & 7.95 & 7.81 & 7.6 \\
\hline yield displacement; $\Delta_{\mathrm{y}^{+}}(\mathrm{mm})$ & 32.22 & 28.67 & 27.4 \\
\hline yield moment; $M_{y+}(\mathrm{KN} . \mathrm{m})$ & 18.68 & 18.35 & 17.86 \\
\hline yield lateral rotation; $\varphi_{y+}(\mathrm{Rad})$ & 0.0129 & 0.0115 & 0.011 \\
\hline maximum load; $P_{\max +}(K N)$ & 14.65 & 20.92 & 21.14 \\
\hline ultimate displacement; $\Delta_{u+}(\mathrm{mm})$ & 122.72 & 149.82 & 223.5 \\
\hline maximum moment; $M_{y+}(\mathrm{KN} . \mathrm{m})$ & 34.42 & 49.2 & 49.67 \\
\hline ultimate lateral rotation; $\varphi_{u+}(\mathrm{Rad})$ & 0.0491 & 0.06 & 0.0894 \\
\hline ductility coefficient; $\mu_{u+}$ & 3.81 & 5.2 & 8.1 \\
\hline rotational capacity; $\varphi_{p+}($ Rad $)$ & 0.0362 & 0.0485 & 0.0784 \\
\hline yield load; $\mathrm{P}_{\mathrm{y}-}(K N)$ & 8.50 & 9.51 & 8.65 \\
\hline yield displacement; $\Delta_{\mathrm{y}-}(\mathrm{mm})$ & 35.26 & 34.26 & 30.29 \\
\hline yield moment; $M_{y-}(\mathrm{KN} . \mathrm{m})$ & 19.98 & 22.35 & 20.33 \\
\hline yield lateral rotation ; $\varphi_{y-}(\mathrm{Rad})$ & 0.0141 & 0.0137 & 0.0121 \\
\hline maximum load; $P_{\max -}(K N)$ & 15.08 & 20.73 & 21.07 \\
\hline ultimate displacement; $\Delta_{u-}(\mathrm{mm})$ & 123.73 & 146.56 & 221.67 \\
\hline maximum moment; $M_{y-}(\mathrm{KN} . \mathrm{m})$ & 35.44 & 48.72 & 49.52 \\
\hline ultimate lateral rotation; $\varphi_{u-}(\mathrm{Rad})$ & 0.0495 & 0.0586 & 0.0887 \\
\hline ductility coefficient; $\mu_{u-}$ & 3.51 & 4.28 & 7.32 \\
\hline rotational capacity; $\varphi_{p-}(R a d)$ & 0.0354 & 0.0449 & 0.0766 \\
\hline
\end{tabular}

Table 5: Performance indicators of the models under cyclic load.
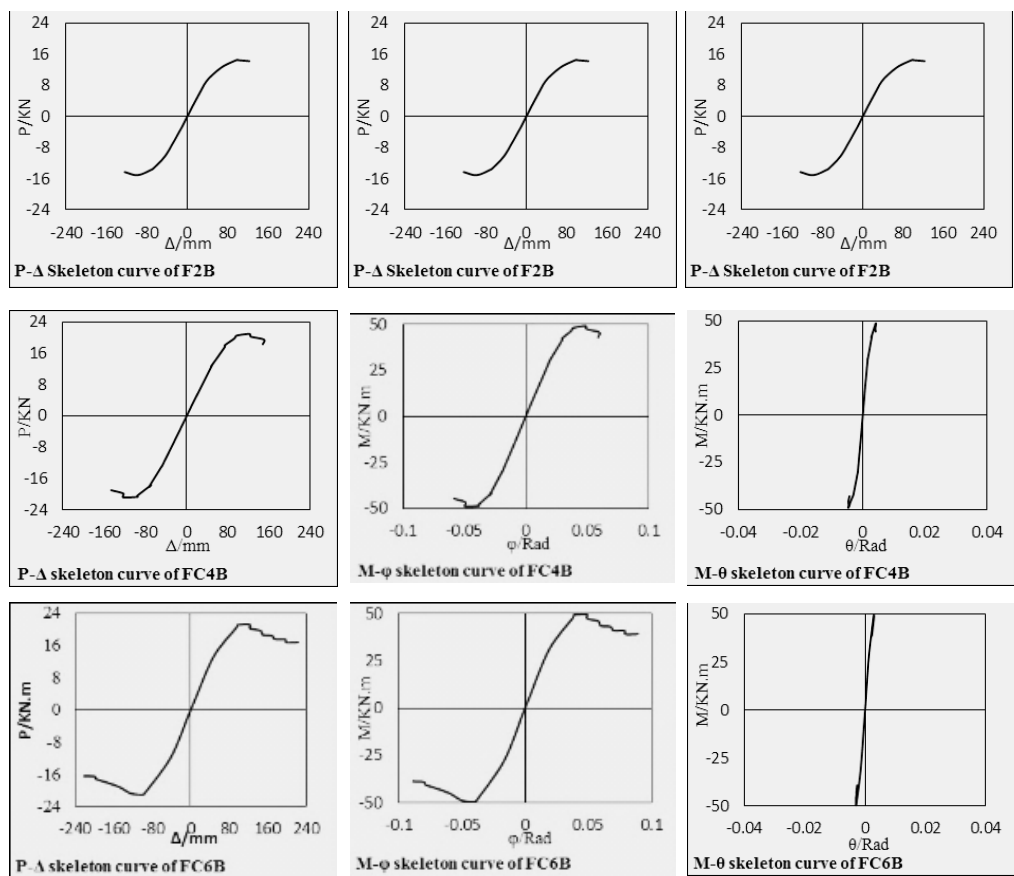

Figure 14: $\mathrm{P}-\Delta, \mathrm{M}-\theta, \mathrm{M}-\varphi$ skeleton curves. 
the model stiffness (i.e., the slope of the beginning of the $\mathrm{M}-\theta$ skeleton curve) by the upper limit of the AISC code (i.e., 20EI/L). The FC6B has the highest rigidity of $140 \%$ and the $\mathrm{F} 2 \mathrm{~B}$ has the lowest rigidity of $77 \%$. FC4B and FC6B models with a rigidity of $124 \%$ and $140 \%$, respectively, regarding the rigidity of $100 \%$ are fully restrained, and F2B model with a rigidity of $77 \%$, regarding the rigidity less than $100 \%$ and more than $10 \%$ is partially restrained. Therefore, in the models the more is the number and cross-section of the BF bolts, the more will be the connection rigidity making it a better choice to be used in seismic specific moment frames. Thus, the effect of BF bolt cross-section on the connection rigidity is quite evident.

\section{Ductility}

Table 5 shows the ductility of different models found using the related coefficients. As shown, the ductility coefficients of models in both positive and negative cases are more than 3.5. BF bolt increased cross-section in the models has caused considerable increase in the ductility coefficient meaning that, in terms of ductility, the models meet the AISC seismic requirements for special moment frames; the higher is the $\mathrm{BF}$ bolt cross section, the more these requirements are met.

\section{Rotational capacity}

The rotational capacity is obtained from Eq. 4 ; the $M-\varphi$ curves in Figures 13 and 14 represent the ultimate rotation of various models and, as shown, all models have ultimate rotations greater than $4 \%$. Rotational capacities of different models shown in Table 5 are all greater than $3 \%$. Therefore, considering that all models have ultimate rotations above $4 \%$ and rotational capacities more than $3 \%$, they all meet the AISC seismic requirements for special moment frames. Effect of increased BF bolt diameter on the connection rotational capacity is considerable and, as shown in Table 5, this increase has caused the FC6B model to have an ultimate rotation greater than $8 \%$ and a rotational capacity more than $7 \%$.

\section{Moment capacity}

Table 4 shows different models' moment capacities found from the $M-\varphi$ curve (Figure 14) by determining the bending moment corresponding to $4 \%$ total story drift. Bending moment corresponding to $4 \%$ total story drift is directly related to the BF bolt cross-section; as shown in Table 4, an increase in cross-section increases the moment capacity. In the F2B model, since BF bolt cross-section is less compared to other models, bending moment corresponding to $4 \%$ total story drift is less than $80 \%$ of the beam plastic moment and, hence, this model does not meet the AISC seismic requirements for special moment frames. In other models, the bending moment corresponding to $4 \%$ total story drift is more than $80 \%$ of the beam plastic moment and, hence, they meet the AISC seismic requirements for special moment frames.

\section{Maximum force and moment; ultimate displacement and ro- tation}

Table 5 shows the maximum force/moment and ultimate displacement/rotation of the models; as shown, they increase with an increase in the BF bolt cross-section. A $100 \%$ increase in the BF bolt cross-section in FC4B model, increases the maximum force/ moment about $43 \%$ and the ultimate displacement/rotation about $22 \%$ compared to the F2B model. A $200 \%$ increase in the BF bolt crosssection in FC6B model, increases the maximum force/ moment about $44.3 \%$ and the ultimate displacement/rotation about $82 \%$ compared to the F2B model. And, an increase of $50 \%$ in the BF bolt cross-section in FC6B model increases the maximum force/moment about $1.05 \%$ and the ultimate displacement/rotation about $49.2 \%$ compared to the FC4B model.

Therefore, it can be concluded that before the maximum force/ moment reaches the beam plastic force/moment ensuring a flexible fracture (beam failure), an increase in the BF bolt cross-section considerably increases all such performance indices as rigidity, moment capacity, maximum force/moment, ultimate displacement/ rotation, rotational capacity, and ductility. But after flexible fracture, an increase in the BF bolt cross-section will cause a very small increase in such force indices as the maximum force/moment; other performance indices including rigidity, ultimate displacement/rotation, rotational capacity, and ductility increase significantly.

\section{Conclusions}

The novel prefabricated bolted beam-to-column connection (BBCC) has been proposed with a preferred support and adding a covering plate to enhance the number/diameter of $\mathrm{BF}$ bolts and more economic efficiency. The models were validated using a similar tested connection. To determine the effects of the BF bolts on the connection behavior, three models were presented. The following results have been obtained through the FE analyses of the three connection models, their $\mathrm{P}-\Delta, \mathrm{M}-\theta$, and $\mathrm{M}-\varphi$ hysteresis and skeleton curves, and the related presented Tables:

1. The failure modes in all connection models show that plastic hinge is formed in the beam. Failure occurs in either the beam or the BF bolts depending on the adequacy or non-adequacy of the cross-sectional area of the BF bolts.

2. The connection behavior is quite sensitive to the BF bolts cross-section; an increase in the BF bolts cross-section causes a significant change in the connection behavior and all such AISC seismic requirements for special moment frames as failure mode, rigidity, ductility, moment capacity, rotational capacity, and ultimate rotation are met.

\section{Acknowledgment}

The authors wish to acknowledge the financial support of the University of Sistan and Baluchestan that made this research possible.

\section{References}

1. Dubina D, Stratan A (2002) Behavior of Welded Connections of Moment Resisting Frames Beam-to-Column joints. Eng Struct 24: 1431-1440.

2. Mirghaderil SR, Dehghani Renani M (2008) The Rigid Seismic Connection of Continuous Beams to Column. J Constr Steel Res 64: 1516-1529.

3. Simoes-da-Silva L, Lima L, Vellasco P, Dendrade S, DeCastro RA (2008) Nonlinear Dynamic Analysis of Steel Portal Frames with Semi-Rigid Connections. Eng Struct 30: 2566-2579.

4. Tagawa H, Liu Y (2014) Stiffening of bolted end-plate connections with stee member assemblies. J Constr Steel Res 103: 190-199.

5. Wang J, Guo S (2012) Structural performance of blind bolted end plate joints to concrete-filled thin-walled steel tubular columns. Thin walled Struct 60: 54-68.

6. Gerami M, Saberi H, Saberi V, Saedi Daryan A (2011) Cyclic behavior of bolted connections with different arrangement of bolts. J Constr Steel Res 67: 690705.

7. Prinz GS, Nussbaumer A, Borges L, Khadka S (2014) Experimental testing and simulation of bolted beam-column connections having thick extended endplates and multiple bolts per row. Eng Struct 59: 434-447.

8. Grimsmo EL, Clausen AH, Langseth M, Aalberg A (2015) An experimental study of static and dynamic behaviour of bolted end-plate joints of steel. Int $\mathrm{J}$ Impact Eng 85: 132-145.

9. Abidelah A, Bouchaïr A, Kerdal DE (2012) Experimental and analytical behavior 
Citation: Alifazl AN, Reza GM, Naser S, Hammed GA (2018) Evaluation of Beam-Flange (BF) Bolts on Behavior of New BBCC Connection with Preferred Support in Modularized Prefabricated Steel Structures. J Steel Struct Constr 4: 142. doi: 10.4172/2472-0437.1000142

Page 12 of 12

of bolted end-plate connections with or without stiffeners. J Constr Steel Res. 76: 13-27.

10. Fang C, Yam MCH, Lam ACC, L Xie (2014) Cyclic performance of extended end-plate connections equipped with shape memory alloy bolts, J Constr Steel Res 94: 122-136.

11. Chen CC, Lin CC, Tsai CL (2004) Evaluation of reinforced connections between steel beams and box columns. Eng Struct 26: 1889-1904.

12. Gholami M, Deylami A, Tehranizadeh M (2013) Seismic performance of flange plate connections between steel beams and box columns. J Constr Steel Res 84: 36-48.

13. Mirghaderi SR, Torabian S, Keshavarzi F (2010) I-beam to box-column connection by a vertical plate passing through the column. Eng Struct 32: 2034 2048.

14. Torabian S, Mirghaderi SR, Keshavarzi F (2012) Moment-connection between I-beam and built-up square column by a diagonal through plate. J Constr Steel Res 70: 385-401.

15. Rezaeian A, Jamal-Omidi M, Shahidi F (2014) Seismic behavior of ConXL rigid connection in box-columns not filled with concrete. J Constr Steel Res 97: 79-104.

16. Liu XC, Pu SH, Zhang AL, Xu AX, Ni Z, Sun Y, Ma L (2015) Static and seismic experiment for bolted-welded joint in modularized prefabricated steel structure. J Constr Steel Res 115: 417-433.
17. Liu XC, Xu AX, Zhang AL, Ni Z, Wang HX, Wu L (2015) Static and seismic experiment for welded joints in modularized prefabricated steel structure. $J$ Constr Steel Res 112: 183-195.

18. Liu XC, Pu SH, Zhang AL, Zhan XX (2017) Performance analysis and design of bolted connections in modularized prefabricated steel structures. J Constr Steel Res 115: 360-373.

19. Azizi Naserabad A., Ghasemi MR, Shabakhty N, Ghohani Arab H (2015) patent Prefabricated BBCC connection for using in bolted steel structures, patent office, Tehran, Iran, Patent Record number 86310.

20. Azizi Naserabad, A Ghasemi MR, Shabakhty N, Ghohani Arab H (2018) Evaluation of Three Support Shapes on Behavior of New Bolted Connection BBCC in Modularized Prefabricated Steel Structures. Int J Steel Struct.

21. AISC/ANSI 34 (2010). Seismic Provisions for Structural steel Buildings. American Institute of Steel Construction, Inc, Chicago, IL.

22. AISC/ANSI360 (2010) Specification for Structural Steel Buildings. American institute of Steel Construction, Inc, Chicago, IL.

23. Maggi YI, Gonçalves RM, Leon RT, Ribeiro LFL (2005) Parametric analysis of steel bolted end plate connections using finite element modeling. J Constr Steel Res 61: 689-708

24. ABAQUS (2017) User's Manual Version 2017. Hibbitt, Karlsson \& Sorensen, Inc: Pawtucket, RI. 